\title{
Análisis y teoría política en las reformas sociales de Solón de Atenas
}

\author{
Salvador Rus RuFINO
}

Recibido: 3 de marzo de 2014

Aceptado: 4 de agosto de 2014

\section{RESUMEN}

La figura de Solón es crucial en el desarrollo del pensamiento político griego. Este fue capaz de desarrollar una teoría política extraída a partir de su experiencia de gobierno, de su análisis de la realidad social y de su actuación como arconte con amplios poderes en una situación crítica durante los inicios del siglo sexto a. e. c. Tomando esto como punto de partida, el propósito de este trabajo es presentar unas conclusiones con relación al análisis que Solón realiza de las circunstancias históricas y sociales en las que desempeñó su responsabilidad política. El mismo le llevó a desarrollar unas ideas que configuraron su teoría política, quizá la primera en la historia del pensamiento, que sirvió para fundamentar sus leyes y justificar sus decisiones como personaje público y responsable del gobierno de Atenas. Todo ello está recogido en sus poemas y en los testimonios posteriores que poseemos de él.

\section{PALABRAS CLAVE}

Solón de Atenas, teoría política, Grecia clásica, análisis político.

\begin{abstract}
The figure of Solon is crucial in the development of Greek political theory. His theoretical contribution arises from his own experience in government, his deep knowledge of the Athenian social milieu and his role as ruler at a critical stage in the early sixth century B.C.E. The purpose of this article is to present some conclusions regarding Solon's analysis of his historical and social reality, which led him to develop several key ideas that shaped one of the earliest political theories of Western thought. Solon's theory served to validate his activity and justify his decisions as both a government leader and a public figure. All this is reflected in his poems and in certain works of later authors.
\end{abstract}

\section{KEY WORDS}

Solon of Athens, political theory, Classical Greece, political analysis. 


\section{INTRODUCCIÓN}

Solón ( $c a .640-560$ a. e. c.), a partir de sus fragmentos poéticos y otros testimonios conservados en la literatura griega, nos ha legado un método para ejercer las responsabilidades de gobierno en una comunidad. Primero, observó de forma crítica la grave crisis social y política de Atenas para comprender sus causas y sus efectos; segundo, analizó los hechos y ponderó las posibilidades y los medios de los que disponía para resolver cada problema; tercero, formuló los principios teóricos ${ }^{1}$ que sirvieron para fundamentar las soluciones propuestas y convencer a los ciudadanos de que esas eran las mejores y más convenientes; y, por último, en cuarto lugar, propuso una forma de estado y de gobierno que fuera adecuada a la estructura social, política y jurídica que conocemos como polis.

De este modo, la obra poética de Solón marcó una diferencia con sus antecesores, porque en ella comenzó a dominar el aspecto explicativo y sistemático sobre el sentimiento personal. Su corpus denotó una percepción y una explicación de los acontecimientos y de los problemas vividos en absoluto convencionales. Recogió sus opiniones e ideas fundamentales de forma coherente con el análisis que realizó. Argumentó racionalmente las soluciones concretas a los problemas. $\mathrm{Su}$ análisis de la realidad social partió de lo particular — los problemas de Atenas- y se elevó hacia lo general — los conceptos e ideas políticas-. Su proceso intelectual fue, por tanto, desde el análisis y el conocimiento de una situación crítica, a la formulación de una teoría basada en conceptos aplicables a la comunidad política ateniense. Finalmente, con su poesía proporcionó a los hombres un modelo de formulación teórica de los problemas políticos que pretendió proyectar más allá de un tiempo y unas circunstancias concretas.

La teoría política de Solón tuvo su fuente de inspiración en la experiencia personal vivida como ser humano, como ciudadano y como gobernante político. Sus fragmentos poéticos recogen las ideas que justificaron su propósito político: reconstruir de manera estable una comunidad humana compleja. Para ello, era necesario establecer vínculos entre los ciudadanos, con el fin de unirlos y comprometerlos en torno a diferentes proyectos políticos comunes beneficiosos para todos y, también, para el establecimiento y el desarrollo de una Atenas dotada de instituciones estables en el interior y fuerte de cara al exterior. Del mismo modo, las muchas reformas políticas y legislativas que llevó a cabo constituyen el espacio público donde se visualizan los principios de su teoría política.

${ }^{1}$ Kurt A. RaAflaub, “Die Anfänge des politischen Denkens bei den Griechen”, en Iring FetCHER y Herfried MÜNKLER (eds.), Pipers Handbuch der politischen Ideen, Vol. 1, Piper Verlag, München, 1988, pp. 234-239. 
Solón utilizó la poesía para transmitir a sus lectores y oyentes unas ideas y unos mensajes determinados. Pero este uso instrumental de la lírica no ha de oscurecer los retos que él mismo se propuso. Entre otros, la reconstrucción y la renovación de la política, tanto en el orden teórico como en su dimensión práctica, que provocó una auténtica revolución intelectual y social. Todo ello partiendo de la realidad histórica en la que se encontraba y resistiendo a las tentaciones que le hubieran llevado, bien a ejercer la tiranía, acaparando el poder absoluto, bien a plantear una utopía como solución ideal a los males de la polis.

Su proceder fue más efectivo, por lo que se convirtió en el ejemplo y la guía de otros gobernantes y legisladores, tanto en Grecia como en Roma ${ }^{2}$. La idea principal que sustenta toda su teoría es que la política es fruto de los hombres que viven en la ciudad, no es obra directa de los dioses por más que estos se interrelacionen con el ser humano. La clave está en formar y desarrollar la capacidad racional, la inteligencia (noûs) con la que uno es capaz de tomar consciencia del entorno, comprender las situaciones, encontrar soluciones a los problemas, construir la polis, proceder a reformarla y redactar leyes que tengan como base la justicia (díke). Y el hombre, en su condición de ciudadano, es el único ser capaz de actuar conforme los dictados de su razón. Esta posición doctrinal introdujo una importante innovación en la política: la consideración, por vez primera, de que el ciudadano es un ser capaz de alcanzar las metas que se propone individual y socialmente, como creador, renovador e innovador de su espacio político. Un ser capaz de transformar una realidad que no le satisface y construir una nueva comunidad que, aunque no cubra tampoco plenamente sus necesidades, exigencias y aspiraciones, es mejor que la precedente.

Ello explica que Solón fuera estudiado y permaneciera en la memoria histórica de una manera continuada desde el mundo helénico hasta los albores del siglo veintiuno, donde se ha producido un inusitado interés por su obra, que se ha vuelto a traducir, comentar y estudiar ${ }^{3}$. La poesía de Solón ha trascendido por-

${ }^{2}$ Walter EDER, "The political significance of the codification of law in archaic societies. An unconventional hypothesis", en Kurt A. RaAflaub (ed.), Social Struggles in Archaic Rome. New Perspectives on the Conflict of the Orders, California University Press, Berkeley, 1986, pp. 262-300.

${ }^{3}$ Véase como ejemplos: Charlotte SchUBER, Solon, Francke, Tübingen, 2012; John D. LEwIS, Solon the Thinker. Political Thought in Archaic Athens, Duckworth, London, 2006; Maria NousSIA-Fantuzzi, Solon the Athenian. The Poetic Fragments, Brill, Leiden, 2010; Christoph MÜlke, Solons politische Elegien und Iamben (Fr. 1-13, 32-37 West). Einleitung, Text und Übersetzung, Kommentar, Teubner, Leipzig, 2002; Elizabeth K. IRwIN, Solon and the Early Greek Poetry. The Politics of Exhortation, Cambridge University Press, Cambridge, 2005; Joseph A. AlmEIDA, Justice as an Aspect of the Polis Idea in Solon's Political Poems, Brill, Leiden, 2003; Josine H. BLoK y André P. M. H. LARDINOIS (eds.), Solon of Athens. New Historical and Philological Approaches, Brill, Leiden, 2006. 
que ha ayudado a muchas generaciones a comprender el devenir peculiar del ser humano, destinado a vivir y convivir con otros. Desde su atalaya poética - surgida en un tiempo extraordinariamente crítico y difícil一, Solón habló con palabras nuevas y renovadas a cada uno de los atenienses, recurriendo a la lírica con la pasión de quien se siente en la obligación de solucionar los graves problemas que amenazaban la existencia de su polis y ahogaban la vida de sus conciudadanos ${ }^{4}$. Solón consideró la corrupción de un régimen político una consecuencia de la deficiente percepción de la realidad, que lleva a tomar malas decisiones y soluciones en un momento concreto. Estableció una estrecha relación entre pobreza, esclavitud, tiranía y crisis social y política con la fuerza (krátei), afirmando que las primeras son los efectos de la última. Por esta razón, dice en sus versos que trata de aunar la violencia y la justicia (bian te kaì díken) ${ }^{5}$, para conseguir restaurar la ciudadanía política y la libertad de los ciudadanos, sometiéndolos a una ley consecuente con un sentido coherente de la igualdad. Finalmente, fue capaz de introducir en el dominio de la praxis política conceptos como, por ejemplo, hesichía (calma, paz, sosiego social), dike (justicia) y eunomía (buen gobierno, buenas leyes). Principios que fueron fundamentales para justificar y alentar el compromiso de los ciudadanos para actuar en favor de la comunidad de forma coordinada y cooperativa. Desde estos presupuestos, y manteniendo su coherencia personal, descalificó a la tiranía en sus diversas manifestaciones, aunque sus reformas no impidieron la posterior instauración de la misma por parte de Pisístrato (ca. 607-527 a. e. c.).

Solón se considera uno de los poetas arcaicos que cuidó mucho la forma de expresarse, buscando en cada poema las palabras y las frases más eficientes para el fin que se proponía ${ }^{6}$. Además de poeta, fue también un hombre de Estado, competente en un doble sentido. Por un lado, ofreció reflexiones teóricas sobre la naturaleza de la polis, evocadas desde su compromiso político como un ciu-

${ }^{4}$ Michael STAHL, "Solon F 3D. Die Geburtsstunde des demokratischen Gedankes": Gymnasium, n. ${ }^{\circ} 99$ (1992), pp. 385-408.

${ }^{5}$ Solón, fragmento 24.16. La traducción y las citas corresponden a la edición bilingüe de Francisco RodrígUEZ AdRAdos, Líricos griegos, elegíacos y yambógrafos arcaicos, Vol. I, CSIC, Madrid, 1981. Existen otras ediciones como la clásica de Ernst DiEHL, Anthologia lyrica Graeca, Teubner, Leipzig, 1925; Martin L. WeSt, Delectus ex iambis et elegis graecis, Oxford University Press, Oxford, 1980; Bruno Gentili y Carlo Prato (eds.), Poetarum Elegiacorum Testimonia et Fragmenta 1, Teubner, Leipzig, 1988 y Juan FerRaté, Líricos griegos arcaicos, El Acantilado, Barcelona, 2000, que siguen otra numeración aunque a veces coinciden.

${ }^{6} \mathrm{La}$ calidad de sus versos era muy estimada en la Antigüedad. Este aprecio lo resume muy bien Platón, Timeo $21 \mathrm{c}$-d, cuando uno de los participantes del diálogo expresa aquella antigua opinión según la cual ni Hesíodo, ni Homero, ni ningún otro poeta habrían logrado más fama que Solón si este se hubiera dedicado completamente a la poesía. 
dadano involucrado en la problemática de su tiempo, instigado por una de las peores crisis políticas y sociales sufridas en Atenas. Por otro lado, supo interpretar y llegar a soluciones basadas en principios morales y jurídicos con un razonamiento lógico surgido de una reflexión de la naturaleza política y social del ser humano, que actúa de forma libre y asume las consecuencias de sus actos ${ }^{7}$.

Pero también fue decisiva en la formación de su teoría política la experiencia alcanzada en el ejercicio de su responsabilidad como arconte (594-593 a. e. c. $)^{8}$. El cargo le impuso la necesidad de formular y comunicar a los atenienses objetivos políticos alcanzables en busca del máximo beneficio para el mayor número de ciudadanos. En este sentido, las reformas de Solón introdujeron cambios significativos en la forma de gobierno y la sociedad del Ática. Por esta razón se le recordó durante siglos como el político que contribuyó a pacificar una comunidad social compleja en un momento crítico, mediante unas leyes justas y el establecimiento en la polis de unas instituciones estables.

\section{El ANÁLISIS DE SU ÉPOCA HISTÓRICA Y CIRCUNSTANCIAS POLÍTICAS}

Solón ${ }^{9}$ nació en torno al 640 a. e. c. y murió en el año 560 a. e. c. Su poesía, pese a estar fragmentada en poco más de trescientos versos, nos proporciona algunos datos importantes sobre su vida, circunstancias, ambiciones y actividad política. Se completa con la información que nos han legado otros testimonios como Aristóteles (ca. 384-322 a. e. c) en la Constitución de los atenienses y en la Política, Plutarco ( $c a .350-432$ a. e. c.), que dedicó a Solón una de sus biografías ${ }^{10}$ y Diógenes Laercio (ca. 215-250 a. e. c.) en su primer libro Vidas, opiniones y sentencias de los filósofos más ilustres. De él se sabe que fue un ateniense perteneciente

\footnotetext{
${ }^{7}$ Solón, fragmento 1.

${ }^{8}$ Solón fue elegido arconte porque era de familia aristocrática y en su tiempo el arcontado estaba reservado a los nobles y ricos. Como afirmó Aristóteles en la Constitución de los atenienses 5.2, "lo hicieron de común acuerdo mediador y arconte y le confiaron la constitución", véase también en la misma obra el fragmento 3.1-3. Sobre su elección como arconte, véase también: Domínguez Monedero, Solón de Atenas, p. 49; Malcolm F. McGregor, "Solon's Archonship. The Epigraphic Evidence", en Polis and Imperium. Studies in Honor of E. T. Salmon, Hakkert, Toronto, 1974, pp. 31-34; Robert Develin, "The election of archons from Solon to Telesinos": L'Antiquité Classique, n. ${ }^{\circ} 48$ (1976), pp. 455-468.

${ }^{9}$ Es muy interesante el resumen de los aspectos más importantes de la vida de Solón de Heinrich Begemann, Quaestiones Soloneae. Specimen I, Typis Zickfeldtii, Hottesmindae, 1875; Konrat ZIEGLER, "Solon als Mensch und Dichter": Neue Jahrbücher für des klassische Altertum n. ${ }^{\circ} 49-50$ (1922), p. 194; Adolfo J. Domínguez Monedero, Solón de Atenas, Ariel, Barcelona, 2011, p. 11. Solonis.

${ }^{10}$ Plutarco escribió el testimonio más largo y completo que poseemos sobre Solón en su Vita
} 
a una familia noble y muy distinguida. Según Plutarco, descendía por línea paterna del rey Codro ( $c a .1160$ - 1132 a. e. c) ${ }^{11}$. Por parte materna pertenecía a la familia de Pisístrato ${ }^{12}$, quien, como ya se ha dicho, instauró una tiranía en el año 561 a. e. c, al parecer, en vida aún de Solón

En lo que concierne a sus actividades políticas los atenienses le reconocieron un gran talento y una gran habilidad. Su fama se acrecentó en el inicio y durante el desarrollo del conflicto contra la ciudad de Megara por el dominio de la isla de Salamina, que era un lugar estratégico fundamental para ambas ciudades. Los crueles combates arrojaron un resultado muy negativo para los atenienses. Por esta razón, se publicó un decreto por el que se condenaba a muerte a cualquier persona que animara la continuidad de la guerra con la conquista e incorporación de la isla al territorio del Ática. Según Plutarco, Solón deseaba alentar a los ciudadanos en aquel propósito. Su manera de no vulnerar la ley fue aparentar en la concurrida plaza del mercado ser un demente tocado con una corona. Allí ordenó a un heraldo leer en voz alta su elegía sobre Salamina, en la que conminaba a los atenienses a volver a empuñar las armas y luchar por la victoria que se les había escapado de las manos. De este modo, movidos y liderados por Solón, lograron su propósito: expulsar los habitantes de Megara y conquistar la isla de Salamina ${ }^{13}$.

La poesía de Solón buscó remover la conciencia de los ciudadanos y convencerlos de la necesidad de acometer reformas profundas en los ámbitos político, económico, social y jurídico, que eran más convenientes e inexcusables en ese momento para garantizar la supervivencia y la estabilidad de la polis. El texto lírico dirigido al pueblo incluía una efectiva apelación a aquellos aspectos sentimentales capaces de sensibilizar a los atenienses para iniciar una lucha con el convencimiento de la victoria final ${ }^{14}$.

${ }^{11}$ De acuerdo con una tradición muy controvertida, Codro fue el último monarca de Atenas. Después de él se abolió la monarquía y se introdujo la figura del arconte.

${ }^{12}$ Diodoro Sículo, Libro IX, 1; Plutarco, Solón 1,2 y 78 e; Diógenes Laercio I, 45 y Scholia Platón, República 599 e.

${ }^{13}$ Solón, Elegía 2; Plutarco, Vidas Paralelas. Solón, 8-10; Diógenes Laercio, Solón 4648; Frankel Hermann, Dichtung und Philosophie des frühen Griechentums. Eine Geschichte der griechischen Literatur von Homer bis Pindar (1951), Beck, München, 1962.

${ }^{14}$ En la elegía parcialmente conservada sobre Salamina, podemos deducir que Solón en lugar de realizar discursos públicos, como harán posteriormente otros políticos atenienses, utilizó con habilidad su poesía para conseguir comprometer a los atenienses en los proyectos sociales y políticos. Sobre este sentimiento de Solón se puede consultar Louise-Marie L'HOMME WérY, "La notion de patrie dans la pensée politique de Solon": L'Antiquité Classique, n. ${ }^{\circ} 69$ (2000), pp. 21-41. 
Poco tiempo después, alrededor del año 600 a. e. c., la situación política y social del Ática se convirtió en más precaria e inestable. La abolición de la monarquía hacia los años 683-682 a. e. c. abocó a Atenas a establecer un régimen controlado de forma oligárquica por las antiguas familias aristocráticas. Este sector de la población ocupó los cargos y las magistraturas de la polis, favoreciendo una reorganización de la vida social y económica conforme a los valores aristocráticos. Fue un modelo que fracasó porque provocó la ruina y el colapso del Ática, situando la región al borde de su extinción.

La consecuencia más grave de esta crisis fue para las clases sociales más desfavorecidas. Se vieron desposeídas de sus bienes y permanecieron excluidas de la actividad y de los cargos políticos. Probablemente, al principio, los atenienses más pobres quedaron adscritos a las distintas familias nobles como una especie de colaboradores. Por su parte, el grupo social denominado hektemóroi ${ }^{15}$ padecieron un tipo de servidumbre y sumisión total a sus amos hasta que Solón abolió esta institución ${ }^{16}$. Además, en Atenas, que representaba el núcleo político más importante del Ática, los conflictos entre las familias nobles e influyentes provocaron la división de la polis en facciones enfrentadas e irreconciliables. Las querellas entre estos clanes fueron frecuentes y en muchas ocasiones se impuso el más fuerte, el que más poder acumulaba sobre el más débil ${ }^{17}$. Esta circunstancia sirve para justificar las razones por las que Dracón ( $c a$. siglo séptimo a. e. c.), célebre legislador anterior a Solón, instauró en Atenas, en el año 624 a. e. c., un código penal tan riguroso. Con todo, esta codificación escrita de las leyes, así como la fundación de una jurisprudencia reguladora de los casos de homicidios, permitió garantizar una cierta seguridad jurídica a los ciudadanos ${ }^{18}$. Fue, sin duda, el primer paso en el largo camino hacia la consolidación de las reformas

${ }^{15}$ Kurt von Fritz, "The Meaning of Hektemoros": Transactions of the American Philological Association, n. 61 (1940), pp. 54-61; Kurt von FrITz, "Once More the Hektemoroi": Transactions of the American Philological Association, n. 64 (1943), pp. 24-43; Detlef Lotze, "Hektemoroi und vorsolonisches Schuldrecht": Philologus, n. 102 (1958), pp. 1-12; Filippo CAssola, "Solone, la terra e gli ectemori": Past and Present, n. ${ }^{\circ} 19$ (1964), pp. 26-68; Geoffrey S. KIRK, "The hektemoroi of pre-Solonian Athens reconsidered": Historia, n. ${ }^{\circ} 26$ (1977), pp. 369-370; Arnaldo BISCARDI, "Nota minima sugli Ectemoroi", en Aux Origines de I'Hellénisme. La Crete et la Grece. Hommage à H. Van Effenterre, Centre Gustave Glotz, Paris, 1984, pp. 199-214; José Ribeiro Ferreira, "Os hectemoros e sua situâo social", en Esclavos y semilibres en la Antiguëdad Clásica, Universidad Complutense de Madrid, Madrid, 1990, pp. 37-53; Gretchen SCHILs, "Solon and the hektemoroi": Ancient Society, n. ${ }^{\circ} 22$ (1991), pp. 75-90.

${ }^{16}$ Georg Busolt, Griechische Staatskunde. Handbuch der Altertumswissenschaft 4. 1. 1 (1920), Beck, München 1926, pp. 779-783.

${ }_{17}$ Jochen Bleicken, Die athenische Demokratie, Schöningh, Paderborn 1986, pp. 15-20.

${ }^{18}$ Plutarco, Vidas Paralelas. Solón 17, 87 d-e. 
políticas, además del requisito por el que más tarde también la población más pobre lograría participar en la vida política y en el gobierno de la comunidad ${ }^{19}$.

Durante el siglo séptimo a. e. c. la sociedad agraria de Ática sufrió una grave crisis, provocada por una recesión económica que tuvo su origen en los cambios de organización del ejército y en las sucesivas modificaciones de las relaciones económicas. En consecuencia, gran parte de los campesinos y de los arrendatarios con pocos recursos ligados a la producción agrícola fueron cayendo de manera creciente en la miseria hasta hacerse dependientes de los señores. En aquel tiempo, las leyes permitían al deudor ponerse a sí mismo como garantía de pago. Muchos campesinos perdieron su libertad, lo que conllevó que fueran vendidos, deportados o condenados a trabajar como esclavos. Algunos se vieron obligados a vender a sus propios hijos por culpa de la inflexibilidad de las exigencias de sus acreedores. Según Aristóteles, este proceso tuvo como resultado la concentración de la propiedad de la tierra y, por tanto, de la riqueza ${ }^{20}$, que poseía una minoría selecta, exclusiva y rica ${ }^{21}$.

La inestabilidad social se vio agravada por una crisis económica que alumbró una conciencia y una sensibilidad políticas nuevas entre el pueblo y los agricultores sin recursos y esclavizados. La crisis había generado una masa de población obligada a enrolarse en el ejército como combatientes para defender su polis. Además, estos ciudadanos tuvieron que asumir el riesgo de perder la vida en un campo de batalla sin obtener a cambio recompensa alguna sobre el reconocimiento de sus derechos y la participación activa en el gobierno de la polis. A principios del siglo sexto a. e. c. la gran masa de población pobre y la minoría rica se hallaban agrupadas en facciones políticas opuestas e irreconciliables. La primera exigió la condonación de las deudas y la redistribución de la tierra de labor ${ }^{22}$; la segunda luchaba con todos sus medios por mantener sus privilegios. El ambiente de confrontación estaba próximo a una guerra civil.

En estas circunstancias, Solón contaba con la ventaja de no haber participado en las injusticias cometidas por la minoría rica ${ }^{23}$. Además, la reconquista de la isla de Salamina le había proporcionado el respeto y la admiración del pueblo.

\footnotetext{
${ }^{19}$ Plutarco, Vidas Paralelas. Solón 13, 85; Aristóteles, Constitución de los atenienses 2. 1-2.

${ }^{20}$ Aristóteles, Constitución de los atenienses 2. 2.

${ }^{21}$ Plutarco, Vidas Paralelas. Solón 13, 85 a-b.

${ }^{22}$ Aristóteles, Constitución de los atenienses 5. 1-2; Plutarco, Vidas Paralelas. Solón 13 ,

${ }^{23}$ Algunos de sus versos son bien elocuentes de las razones que hay detrás de su conocida autoridad, por ejemplo, cuando trata el tema de la consecución de la riqueza de forma injusta:
} $85 \mathrm{~b}-\mathrm{c}$. Solón, fragmento 1.7-17. 
Los atenienses vieron en él al político que podía resolver sus problemas, por esta razón le propusieron convertirse en tirano, pero no aceptó. En cambio, sí accedió a ser nombrado arconte con amplios poderes reconocidos por un período limitado, desempeñando así un puesto similar al de un aisymnétes ${ }^{24}$. Desde esta posición tenía la posibilidad de actuar como árbitro para dictar resoluciones que pudieran acabar con las posiciones irreconciliables que dividían a los atenienses. Solón recibió el difícil cometido de superar la confrontación entre las clases sociales, buscando una solución que permitiera reconducir la extrema rivalidad entre facciones, compensar los intereses entre ellas y, de este modo, evitar la guerra civil.

El poder concedido a Solón fue similar al de un dictador, cosa que le permitió introducir cualquier tipo de medidas oportunas y necesarias que pudieran cambiar de forma duradera las condiciones sociales y las instituciones políticas que habían causado la crisis en Atenas. El período en el que desempeñó el cargo de arconte (594-593 a. e. c.) sirvió para completar las reformas, dictar las leyes, crear instituciones y establecer los medios con los que llevar a cabo un proyecto político reformador. Solón al final de su mandato logró restablecer la paz y devolver la dignidad a la población más desfavorecida, convirtiendo a los atenienses en ciudadanos con posibilidad de decidir qué forma política querían y qué medios eran los mejores para asegurar la estabilidad y la continuidad de la polis.

\section{LAS REFORMAS SOCIALES Y POLÍTICAS}

Los pobres de una Atenas sumida en una profunda crisis exigieron al arconte la condonación de las deudas y la redistribución de la tierra de labor. Solón cumplió con la primera demanda y puso en marcha un programa que se conoció con el nombre de seisachtheía ${ }^{25}$. Esta resolución ya fue problemática porque algunos

${ }^{24}$ La aisymneteía fue un cargo ya conocido en otras regiones de Grecia, dotado de poderes absolutos, que se caracterizaba por ser una responsabilidad política elegida y consentida por los conciudadanos, aunque temporalmente limitado en la mayoría de los casos. Véase ARISTóteles, Política 1285a, 30-1285b 4.

${ }^{25}$ Aristóteles, Constitución de los atenienses, 6. 1; Plutarco, Vidas Paralelas. Solón 15, 86; Diógenes Laercio, 45. Andreas Gohmann, Solon, Lastenabschüttlung (Seisachtheia) und Politeia, Grin Verlag, München, 2002; Frank J. Frost, "Attic Literacy and the Solonian Seisachtheia": The Ancient World, n. ${ }^{\circ}$ 15/3-4 (1987), pp. 51-58; Nicholas G.L. HAMmond, "The Dates of Solon's Seisachtheia and Nomothesia": Proceedings of the Cambridge Philological Society, n. ${ }^{\circ}$ 169-171 (1938), pp. 10-11, Nicholas G.L. Hammond, "The Seisachtheia and the Nomothesia of Solon": The Journal of Hellenic Studies, n. ${ }^{\circ} 60$ (1940), pp. 71- 83; Nicholas G. L. 
sectores de Atenas la vieron como una injerencia y una extralimitación de las funciones del poder político en la vida privada de los ciudadanos. Proceder al reparto de las tierras habría supuesto transgredir el derecho vigente y, ante todo, abrir una confrontación con los más ricos y los aristócratas. Además, Solón habría sido considerado como un tirano que no ve límites al uso caprichoso del poder que tiene y que alienta toda ilegalidad y depravación políticas.

Solón acostumbraba a celebrar en su poesía el hecho de haber liberado a cientos de ciudadanos de sus deudas. En verdad, quienes se vieron reducidos a la condición de esclavos recuperaron su libertad gracias a los efectos retroactivos de su reforma. Más aún, se propuso y consiguió encontrar y repatriar a muchos atenienses que habían sido vendidos en el extranjero, así como a los que habían huido de sus acreedores ${ }^{26}$.

Las pérdidas económicas causadas por la condonación de las deudas afectaron sobre todo a la aristocracia más poderosa e influyente, que fue, en cierta medida, la causante de los problemas sociales y económicos que sufría Atenas. Solón, invocando como principios fundamentales la libertad, el orden social y la justicia, no dudó ni tuvo miedo de combatir la soberbia y la manera arrogante de proceder de una minoría acostumbrada a imponer su voluntad sobre una mayoría de ciudadanos con muy pocos recursos ${ }^{27}$. De esta forma, Solón restableció unos valores que sirvieron de guía para el desempeño de su responsabilidad política y para orientar las reformas que tenía que acometer. Uno de los principales objetivos de su obra literaria fue esclarecer qué principios morales y jurídicos debían situarse como fundamento de la política, con el fin de prevenir el uso arbitrario del poder y, al mismo tiempo, controlar el desempeño de los cargos públi$\cos$. Sus versos no tienen una intención educadora, ni moralizante, como pretendieron otros poetas anteriores. Para él la virtud por sí misma no genera un efecto social en el individuo, sino que la virtud se debe poner en juego en la comunidad, en las relaciones con otros y en la asunción de los deberes y las obligaciones que se derivan de la condición de ciudadano. La virtud social o ciudadana

Hammond, "Land Tenure in Attica and Solon's Seisachtheiai": The Journal of Hellenic Studies, n. 81 (1961), pp. 76-98; Phillip HARDING, "Androtion's view of Solon's seisachtheia": Phoenix, n. ${ }^{\circ}$ 28 (1974), pp. 282-289; Edward M. HARRIs, “Did Solon Abolish Debt Bondage?”: Classical Quartely, n. ${ }^{\circ}$ 52/2 (2002), pp. 415-430 y Edward M. HARRIS, "A New Solution to the Riddle of the Seisachtheia", en Lynette G. Mitchell (eds.), The Development of the Polis in Archaic Greece, Routledge, London, 1997, pp.103-112; Louise Marie L'Homme WÉRY, "Eleusis and Solon's Seisachtheia": Greek, Roman and Byzantine Studies, n. 40 (1990), pp. 109-134; Pavel Oliva, "Solon und seine Seisachtheia": Zava Antika, n. 21 (1971), pp. 103-122.

${ }^{26}$ SOLÓN, fragmento 24. 8-9.

${ }^{27}$ Solón, fragmentos $23.1-3 ; 11,1-8$. 
evita el desorden que priva a una parte importante de la población de los derechos y que hace que los propios ciudadanos se sientan oprimidos por un poder que se impone. Este es el comportamiento propio en un régimen tiránico que, en un caso extremo, suele llegar a la guerra civil ${ }^{28}$, que era justo lo que Solón y la mayoría de los atenienses quisieron evitar.

Ante todo, en sus versos, Solón reprochaba a los ciudadanos una falta de conciencia a la hora de reflexionar sobre las consecuencias de sus propias acciones, atrapadas a menudo en una "necia esperanza" 29 . Las causas y los efectos de una decisión política debían ponderarse antes de actuar mediante una deliberación pausada, controlando el impulso primario del que suelen derivarse malas consecuencias. Su recomendación no solo iba dirigida a los atenienses de su propia clase social, sino al conjunto de la población, incluidos los más pobres ${ }^{30}$. Solón estaba convencido de que los hombres eran los responsables de su propia infelicidad, a pesar de que los relatos míticos servían para justificar muchas de las actuaciones de los mortales, porque los causantes de la maldad eran los dioses que castigaban las acciones imprudentes o injustas de los seres humanos ${ }^{31}$.

Solón concedió una atención importante al establecimiento de un orden jurídico y político en la polis, introduciendo novedades que no vulneraran el principio de igualdad geométrica propio del ideal aristocrático, según el cual las oportunidades y los derechos de los ciudadanos debían ser proporcionales a sus méritos y valores ${ }^{32}$. Una medida que, sin duda, pretendía evitar una confrontación con esa poderosa clase y con la que buscaba un equilibrio entre la aristocracia y los niveles sociales con menos recursos económicos. Todo esto supuso en la práctica, al final del proceso y contra lo que muchos de sus contemporáneos pensaron, la negación de las principales reivindicaciones exigidas por el pueblo, tanto en lo que respecta a la influencia política como a la redistribución de las tierras de labor pertenecientes a la aristocracia. No obstante, Solón supo compensar este hecho que defraudaba las expectativas puestas en él con otras ventajas y reconocimientos que favorecieron a los más pobres. Por ejemplo, instauró una serie de condiciones que permitían la obtención de ingresos estables a través del trabajo, liberando así a los ciudadanos pobres de la miseria y dependencia económicas. Por su parte, la aristocracia mantuvo su influencia política y

\footnotetext{
${ }^{28}$ Solón, fragmentos 1. 7-16; 8, 1-6.

${ }^{29}$ Solón, fragmento 1. 33-42.

${ }^{30}$ Solón, fragmento 5. 1-5.

${ }^{31}$ Solón, fragmento 24. 20-27.

32 Véase David Levystone, "La Constitution des Athéniens du Pseudo-Xénophon": Revue Française d'Histoire des Idées Politiques, n. ${ }^{\circ} 21$ (2005/1), pp. 3-48, especialmente pp. 35-36.
} 
sus grandes extensiones de tierras, pero se vio obligada a renunciar al cobro de las deudas y al sometimiento de sus deudores a la esclavitud.

En consecuencia, si bien las reformas sociales causaron pérdidas económicas más o menos elevadas en el patrimonio de los nobles, también generaron importantes ventajas a esta clase social. Solón impidió que la población insolvente pudiera perder su libertad y ser esclavizada en el futuro, tal como había sucedido con anterioridad ${ }^{33}$. Juzgó su reforma como justa y se consideró un juez imparcial, aun cuando el alcance práctico de sus medidas fuera insuficiente a la hora de satisfacer todas las demandas de los pobres y, al mismo tiempo, sufriera críticas y ataques por parte de los nobles. Solón vivió una coyuntura política difícil en la que se consideró como el escudo que separaba a dos grupos enfrentados. De ahí que escribiera en uno de sus versos: "Me moví como un lobo rodeado entre los perros" ${ }^{34}$. Circunstancia que le exigía, a un mismo tiempo, cautela y contundencia, tanto a la hora de reponer o reformular con solidez unos principios políticos y jurídicos como de acometer con ellos las reformas más necesarias y urgentes.

Desde una perspectiva política, Solón abolió el viejo régimen de la aristocracia que había degenerado en oligarquía, reemplazándolo por un nuevo orden timocrático. Si durante años los miembros de las familias aristocráticas ocupaban sistemáticamente los cargos políticos, tras la reforma de Solón estos derechos se distribuyeron en función de la cuantía de la propiedad de cada ciudadano. Así, el factor determinante en el reconocimiento del estatus social y de los derechos fue la rentabilidad de los bienes de los ciudadanos. De este modo, Solón dividió la población en cuatro clases censitarias: los denominados pentacosiomédimnos, hippeîs, zeugitas y thêtes. Los miembros de la primera clase debían disponer de una renta anual superior o igual a 500 medimnos de productos agrarios; los hippeîs requerían por lo menos 300 y los zeugîtas no menos de 200 medimnos. Aquellos que tuvieron una renta inferior pertenecían a la clase de los thêtes ${ }^{35}$.

${ }^{33}$ Bernard Randall, Solon Lawmaker of Athens, The Rogen Publishing Group, New York, 2004, para las reformas pp. 50-80; Ron Owens, Solon of Athens. Poet, Philosopher, Soldier, Stateman, Sussex Academic Press, Brighton, 2010, pp. 97-144; Phillip V. StAnLEY, The Economic Reforms of Solon, Scripta-Mercaturae-Verlag, St. Katharinen, 1999; John MATEL, The Social and Economic Reforms of Solon, University of Wisconsin Press, Madison, 1980; Anthony FRENCH, "The Economic Background to Solon's Reforms": The Classical Quarterly, n. o 6/1 (1956), pp. 1125; William J. Woodhouse, Solon the Libertator. A Study of the Agrarian Problems in Attika in the Seventh Century, Octagon Books, New York, 1938.

${ }^{34}$ Solón, fragmento 5. 1-7 y 5. 5 respectivamente.

${ }^{35}$ Domínguez Monedero, Solón de Atenas, pp. 60-63 que afirma que más tarde la tasa de productos agrarios se transformó para su medición en dinero. 
Los zeugitas y los pentacosiomédimnos eran el grupo de ciudadanos mejor armados. A esta clase pertenecieron, sobre todo, los campesinos con suficientes recursos económicos para permitirse comprar una armadura y las armas para formar parte del ejército. A la clase de los hippeîs perteneció la mayor parte de aquellos ciudadanos que podían mantener un caballo. Es indudable que solo, o principalmente, los miembros de las familias aristocráticas eran capaces de reunir tal cantidad de dinero. De esta clase, compuesta por nobles dueños de caballos, Solón separó a los pentacosiomédimnos, cuyos miembros constituían los terratenientes más ricos. En suma, los ciudadanos de la primera clase y, quizá, en cierta medida, también los de la segunda, tuvieron derecho a ocupar los cargos más importantes. Únicamente ellos pudieron convertirse en tesoreros o arcontes. Las magistraturas políticas más importantes se elegían cada año entre los ciudadanos, si bien una porción de cargos se sorteaban entre todos los atenienses. Por su parte, los zeugitas solo podían aspirar a un cargo de bajo nivel. Y a los thêtes no se les permitía responsabilizarse ni acceder a ningún cargo. A esta última clase pertenecieron los artesanos y campesinos con menos recursos económicos $\mathrm{y}$, también, todos aquellos que Solón había liberado de la servidumbre o de la esclavitud en el extranjero.

Aunque Solón no había previsto un derecho de voto pasivo para la población más pobre, los thêtes en la práctica se constituyeron como un grupo capacitado para tomar acuerdos. Su forma de actuar de manera directa en el gobierno de la ciudad fue a través de la asistencia a la Asamblea Popular (ekklesía), a la que podían concurrir todos los ciudadanos. Estrictamente hablando, la Asamblea contaba solamente con el poder de elevar propuestas, modificaciones y añadidos a la legislación ya existente para adaptarla a las nuevas circunstancias que sobrevenían. Además, los que pertenecían a la clase de los thêtes, al no estar instruidos y tener que trabajar todos los días para ganarse el sustento, probablemente ni se plantearon desempeñar una magistratura. Pero, aun así, el reconocimiento de la capacidad y el derecho a participar en la actividad política de este sector de la población, muy numeroso y humilde, es una de las apuestas más arriesgadas e innovadoras llevadas a cabo por Solón. Con esto superaba una dificultad que había lastrado el desarrollo de Atenas: la exclusión de parte de la población de la vida política. El gobierno y la preservación del orden en la polis debían comprometer a todos los ciudadanos con independencia de su riqueza, posición social o formación recibida.

Los thêtes también tuvieron la oportunidad de formar parte de los tribunales de justicia, que en tiempos de Solón constituyeron la primera instancia de apelación. Los atenienses pudieron acudir a este tribunal para recurrir contra sentencias dictadas por los arcontes encargados de las tareas judiciales. Aparte del 
tribunal formado por jurados para tramitar las apelaciones, que era una novedad en Atenas, Solón conservó también el Areópago. Este actuó como un consejo y un tribunal al que pertenecían solamente antiguos arcontes. Se encargó de controlar a los magistrados, interpretar las leyes y tuvo, entre otras responsabilidades, la jurisdicción exclusiva sobre algunos homicidios. Sin embargo, la existencia y el cometido del Consejo de los Cuatrocientos resulta muy controvertida e incierta ${ }^{36}$.

Solón introdujo además del tribunal de jurados otra novedad muy importante en el ámbito judicial: la acción popular. Conforme al derecho antiguo, solamente la persona perjudicada —o, en su defecto, uno de sus parientes - tenía derecho a denunciar al autor de un crimen. Gracias a esta nueva forma de ejercer la acusación cualquier ciudadano estaba legitimado a perseguir al autor de un crimen, siempre que este afectara de manera directa o indirecta el interés público. Con esta innovación Solón pretendió promover un sentido de solidaridad y de responsabilidad dentro del ámbito social y ciudadano. La introducción de la acción popular, junto a la posibilidad de apelar contra una sentencia ante un tribunal compuesto por un jurado, aumentaron, sin duda, la capacidad de los miembros de las clases menos favorecidas a la hora de ver realizadas sus pretensiones dentro de la legalidad. Así pudieron sentirse ciudadanos de pleno derecho, capaces de intervenir e influir en la buena marcha de los asuntos públicos reservados exclusivamente a los nobles.

La justicia en el universo intelectual del tiempo de Solón todavía se atribuía a los dioses. El problema más grave e incluso más urgente en la polis era establecer una justicia humana. Esta exigía juicios realizados por los hombres que se asemejaran a la eficacia de la llamada justicia natural, que es la misma e igual en todo tiempo y lugar. La justicia como virtud humana, norte del legislador y principio de actuación de los tribunales, debía estar presente en todos los cambios sociales y políticos ${ }^{37}$.

Las reformas de Solón consiguieron el objetivo perseguido mediante una serie de leyes que constituyeron la base del derecho ático durante siglos. Dicha legislación cubría una extraordinaria variedad de situaciones, desde el derecho de familia y el derecho de sucesión, hasta los derechos económicos y otras normas jurídicas que tenían como fin mantener la disciplina y la moral políticas. Las noticias que nos han llegado sobre la legislación soloniana muestran que, para él,

\footnotetext{
${ }^{36}$ Solón, fragmento 24. 1-6 y Aristóteles, Constitución de los atenienses 3. 2-6.

${ }^{37}$ Por ejemplo, las sentencias dictadas de manera arbitraria por jueces de una clase elevada, provocaron las críticas y las quejas de otros autores como Hesíodo, Trabajos y Días, 249-251 y 260-263.
} 
fue esencial fortalecer la familia, la unión entre sus miembros, así como garantizar la transmisión y la perdurabilidad de la heredad familiar ${ }^{38}$.

Al mismo tiempo, promocionó el desarrollo económico del Ática mediante unas leyes muy precisas referidas a las importaciones y a la actividad mercantil. Este último objetivo se alcanzó con la reforma y la unificación de las unidades tradicionales de medida y peso y de la acuñación de las monedas ${ }^{39}$. Su intención fue evitar que los ciudadanos malgastaran su tiempo en un empeño excesivo por desear alcanzar y retener los cargos y los puestos en la polis usando cualquier medio. Por esta razón, encargó al Areópago la vigilancia y la planificación del tiempo libre de la población, con capacidad y autoridad para imponer castigos a los ociosos si fuera necesario.

Las medidas políticas y jurídicas también procuraron atraer el establecimiento permanente de comerciantes extranjeros para incrementar la actividad económica de la ciudad. En lugar de confiar toda la prosperidad del Ática a la agricultura, Solón quiso favorecer y concienciar a los ciudadanos de la importancia del comercio para generar riqueza y como fundamento del incremento del dinamismo de la economía. El desarrollo mercantil requiere una producción previa y las reformas contribuyeron a incrementar el prestigio de la actividad industrial, la artesanía y las artes que, junto a una incipiente transformación de los productos agrícolas, aumentó el flujo migratorio del campo a la ciudad por parte los atenienses. La base de la economía siguió siendo la agricultura, pese al intento de diversificar las actividades como vía de consecución de una mayor prosperidad, tanto de la polis como de los ciudadanos. Se autorizó solamente la exportación del aceite porque el abastecimiento del Ática estaba garantizado y había excedente. Para evitar la desmedida concentración de la propiedad se impuso que nadie podía adquirir una propiedad cuyas dimensiones perjudicara a las explotaciones pequeñas y medianas. Por otra parte, aquellos que malgastaran su herencia paterna sufrieron la atimía, es decir, pérdida del honor y privación de derechos cívicos ${ }^{40}$.

Solón trató de mejorar mediante las leyes las condiciones de vida de los atenienses, regulando aspectos de la vida diaria. Pulsó las creencias y aspiraciones de los ciudadanos para decidir qué reformas debía realizar y cuáles omitir; su

${ }^{38}$ Plutarco, Vidas Paralelas. Solón 17-25; Diógenes Laercio, Solón 1. 55-58; AristóteLES, Constitución de los atenienses 10.

${ }^{39}$ Molly Miller, "Solon's Coinage": Arethusa, n. 4 (1971), pp. 25-47 y Mortiner CHAMBERS, "Aristotle on Solon's Reform of Coinage and Weights": California Studies in Classical Antiquity, n. ${ }^{\circ}$ 6, 1973, pp. 1-16.

${ }^{40}$ Plutarco, Vidas Paralelas. Solón 22. 9-21. 91; Diógenes Laercio, Solón 1. 55; AristóTELES, Política 1266b, 17-18. 
legislación se adaptó a las exigencias de la realidad social y política. Para él, lo que jurídica y políticamente debía ser considerado como justo también debía ser adecuado. Por eso, muchas de las medidas propuestas en sus reformas políticas y económicas eran favorables al grupo de ciudadanos más numeroso, los más pobres, débiles y vulnerables. Evidentemente, Solón aspiraba a que cada ciudadano fuese capaz de ganarse la vida de un modo u otro, ya fuera con la actividad agrícola, el comercio o mediante la práctica de un oficio o arte, evitando así su penuria y el riesgo de convertirse en una carga pesada para la polis. Dispuso que únicamente los hijos de padres caídos en la guerra debían obtener el apoyo de la ciudad y vivir a costa del dinero público.

Se trata de medidas con las que buscaba en todo momento la estabilidad económica y social de Atenas, siempre desde una equidistancia admirable tal y como se muestra en sus versos:

Un malvado ambicioso que como yo hubiese tomado en sus manos el aguijón, no habría contenido al pueblo en sus límites; pues si yo hubiese querido lo que entonces deseaban los contrarios, o bien lo que planeaban contra estos los del otro bando, esta ciudad habría quedado viuda de muchos ciudadanos ${ }^{41}$.

\section{LA CONSTRUCCIÓN DE UNA TEORÍA POLÍTICA}

La poesía de Solón no se puede considerar una mera creación literaria. En ella se aprecia tanto un análisis riguroso de la situación social que le tocó vivir, como la defensa y exposición de unas ideas válidas para configurar una teoría política nueva como guía para su acción de gobierno ${ }^{42}$. El propio Solón describió Atenas como una comunidad política que necesitaba de una constitución nueva:

Juntando la fuerza y la justicia tomé con mi autoridad estas medidas y llegué hasta el final, como había prometido; y, de otro lado, escribí leyes tanto para el hombre del pueblo como para el rico, reglamentando para ambos una justicia recta $^{43}$.

En lo que respecta a la reflexión que sirve para formar su conciencia política se planteó preguntas como las siguientes. ¿Cuál es el estado anímico de los atenienses y en qué punto se encuentra su voluntad a la hora de enfrentarse a las

${ }^{41}$ SOLÓN, fragmento 24. 20-26.

${ }^{42}$ Plutarco, Vidas Paralelas. Solón 3. 80a.

${ }^{43}$ Solón, fragmento 24. 15-20. 
situaciones que exigen una reforma? ¿Dónde se encuentra el punto en el que se puede alcanzar un acuerdo entre los ciudadanos y evitar una guerra civil? ¿Qué reformas son convenientes y se pueden poner en marcha y en qué orden temporal?

Solón valoró el escenario, las circunstancias y el ánimo de los atenienses. Del análisis concluyó que los habitantes del Ática se habían dividido en dos grupos que mantenían posiciones irreconciliables y que les imposibilitaba realizar proyectos comunes porque no existía cohesión social ni compromiso político. Uno de los escollos que exacerbaba esta situación estaba en la baja productividad de la tierra y en las deudas acumuladas por los agricultores, que no podían satisfacer con el fruto de su trabajo y la producción. Ambos hechos estaban concatenados.

De su diagnóstico dedujo la existencia de un gran riesgo de ruptura social, ligado a una disfunción política peligrosa que, de llevar a una completa parálisis, bloquearía la más mínima iniciativa de superar la crisis. Una circunstancia que bien podría desembocar incluso en un enfrentamiento armado que dividiera la polis durante generaciones, debilitando a Atenas internamente y de cara al exterior. Por tanto, era necesario fundamentar las reformas y las instituciones políticas sobre unos principios rectores firmes y aceptados por todos, desde los que adoptar con urgencia medidas y mecanismos que permitieran alcanzar una cierta fluidez en las relaciones y que, al mismo tiempo, sirvieran para reconducir las posiciones hacia la unidad y el compromiso entre las partes para lograr definir y desarrollar un mismo proyecto común.

La personalidad y la trayectoria vital de Solón estaban ligadas a la aristocracia ateniense, que era la causante de la división social que se había producido. Las propuestas del arconte generaron entre los nobles una división y un enfrentamiento entre facciones. Las reformas políticas debían asumir la existencia de una división social que era lo que se quería superar. Además de dividir a los ciudadanos mediante indicadores externos de naturaleza material, se propuso distinguirlos por sus cualidades. Por un lado, los honrados (esthloi) o los buenos (agathoi); por otro, los malos $\left(k_{a k o i}\right)^{44}$, sin que ninguno de estos términos describiera cualidades morales. El primer caso designaba a aquellos ciudadanos que habían alcanzado un nivel cultural más alto y que gozaban, al igual que los nobles, de una buena reputación en la sociedad. No era necesario ser rico o aristócrata para ocupar esta categoría. En contraposición, el segundo término se refería a los ciudadanos rudos y sin formación que carecían de ocio porque se veían obligados a trabajar todo el tiempo para conseguir recursos materiales para vivir.

${ }^{44}$ Solón, fragmentos 23. 20-21; 3. 9-10 y 24. 18-19. 
En este grupo estaban todos los que se veían obligados a trabajar para ganarse su sustento o el de su familia. Esta clase recibía a veces la simple denominación de pueblo (dêmos $)^{45}$. La división de la sociedad en diferentes clases no planteó ninguna cuestión referente al origen o sentido de la misma, fue un dato incuestionable con el que debía contar.

La atribución de unas características peculiares a cada clase supuso la acentuación de sus diferencias. Así, por ejemplo, los miembros de la segunda clase los ciudadanos obligados a trabajar - no tenían suficiente capacidad como para asumir responsabilidades de gobierno porque carecían de tiempo y de una formación adecuada. Y, en general, no solían actuar con cordura, pese a que cada uno dispusiera de inteligencia para pensar en lo que le beneficiaba personalmente. Además, eran impresionables y manipulables por las palabras de un hábil y fogoso orador. Dicho de otra manera, el pueblo era ingenuo y se podía dejar influenciar, manejar y dominar fácilmente por un líder que les mostrara una vía cómoda y fácil que solucionara sus problemas. Para evitar esta inestabilidad social necesitaba incrementar, garantizar y mantener un nivel de vida aceptable y acorde a las exigencias mínimas de la dignidad de cada grupo social, teniendo en cuenta que un exceso de prosperidad en personas insensatas desencadenaba la hybris - la altanería y el desenfreno-, que fue una de las causas de la desaparición de la monarquía ${ }^{46}$.

Para Solón, aquellas personas que no tenían suficiente intelecto y que no habían gozado de una educación apropiada y no eran capaces de leer no debían desempeñar ninguna responsabilidad en el gobierno o en la administración pública. Por consiguiente, el derecho a ocupar los cargos más importantes quedaba reservado a la elite, es decir, a los nobles, aunque no se debe de interpretar este criterio en términos absolutos. Solón admitió que la clase de más bajo nivel y más numerosa era apta para tomar algunas decisiones. Por esta razón, se le reconoció el derecho a participar en pie de igualdad en los debates de la Asamblea y prestar su colaboración en el tribunal de apelación ${ }^{47}$.

Por otro lado, Solón apreciaba en la vieja aristocracia una insuficiente conciencia moral y una exigua formación para cumplir de forma adecuada, competente e imparcial las tareas que exigía el gobierno de la polis como unidad política compleja y diversa. Criticó enérgicamente a los miembros de su propia clase,

${ }^{45}$ Solón, fragmentos $10.4 ; 5.1 ; 24.2$ y 25.1.

${ }^{46}$ Solón, fragmentos 5. 5-36; 8. 5-7; 10. 3-4; 24. 22-25. Por esta razón, Solón rechazó la profunda reforma agraria exigida por el pueblo que obligaba a realizar un nuevo reparto de todas las tierras.

${ }^{47}$ SoLÓN, fragmentos 3. 31-39; 5. 1-6. 
les reprochó su codicia, su injusticia, su falta de escrúpulos, así como la soberbia, el orgullo y la jactancia que les llevaba a considerarse superiores e impunes. A pesar de que su crítica también afectó al pueblo, los reproches más severos recayeron contra los nobles. Precisamente, el fracaso de los aristócratas en el gobierno de la comunidad era la razón principal de que el Ática estuviera sumida en una situación miserable y caótica. La clase que debía asumir sus responsabilidades en la dirección de los asuntos políticos no había sido capaz de responder a dichas exigencias, permitiendo que el desorden se apoderase de la ciudad y extendiendo la miseria y las tensiones políticas por doquier.

La visión de Solón sobre la polis, como una realidad moral ordenada por la justicia, le permitió insistir en la idea de que las raíces de la eunomía también se encuentran en las mentes y las actitudes de ciudadanos. De ahí que describiera las consecuencias de la adopción por parte de cada persona de una disposición apropiada para la polis, dando lugar a un programa normativo orientado a la educación de los ciudadanos con el fin de que estos fueran capaces de asumir las responsabilidades propias de su condición, que Solón resume en su elegía que lleva por título Eunomía ${ }^{48}$. Pero en el mismo texto también puso de relieve el contraste entre el buen orden y el desorden o mal gobierno encarnado por la disnomía. Su valoración es muy gráfica:

Estas son las enseñanzas que mi corazón me ordena dar a los atenienses: cómo Disnomía acarrea males sin cuento a una ciudad, mientras que Eunomía lo hace todo ordenado y cabal y con frecuencia coloca los grillos a los malvados ${ }^{49}$.

La disnomía permitió que los individuos actuaran sin rectoría legal, sin sentido de las exigencias que imponen las leyes en las relaciones de unos con otros. Solón afirmó que si unos actúan de forma incorrecta en la ciudad, entonces la polis cae en el desorden y la ilegalidad. Todos en esta coyuntura sufren las consecuencias nefastas de la corrupción, las guerras civiles, la esclavitud y todo tipo de desórdenes.

En cambio, la eunomía supone la integración de varios aspectos de las conductas correctas en la polis. La legalidad convierte todo en perfecto, también puede suprimir la arrogancia y la soberbia de los individuos, fomentando el desarrollo y el progreso de los ciudadanos sin distinción de clase y posición. Así,

${ }^{48}$ Solón, fragmento 4. 30-39. Eunomía significa buen gobierno, orden social y es hija de Zeus al igual que Díke, justicia, e Irene, paz, según Hesíodo, Teogonía 902. En cambio, Disnomía significa mal gobierno y Ate, infortunio, son hijas de Eris, la discordia, Teogonía 230.

${ }^{49}$ SoLÓN, fragmento 4. 30-34. 
la poesía de Solón se convirtió en una guía efectiva de la conducta de los ciudadanos, un daîmon arcaico que orientó las conciencias de los hombres. Un camino para conectar los principios de la polis con las actividades y las acciones diarias de cada persona.

Solón no estableció ningún modelo para todas las cosas, pero él insistió en la necesidad que existe entre los seres humanos de vivir en una polis anclada en la justicia y en los valores que él vio como necesarios y vitales para la comunidad. Concretamente, para su perdurabilidad social, jurídica, política y económica, que era de lo que carecía Atenas en aquel tiempo. En la polis no es suficiente afirmar la existencia de un orden presente. Los valores específicos se van incorporando a un proceso de desarrollo temporal de esta como institución y como realidad política y social, de manera que se van añadiendo unos y perdiendo otros. Por esta razón, Solón no se sintió condicionado ni compelido por los viejos valores de la aristocracia que habían demostrado su falta de adecuación a las nuevas circunstancias políticas, sociales y económicas.

La falta de virtud (areté) de los ricos entregados al yugo devastador de la codicia era para Solón la causa de la inestabilidad política de Atenas. Tras ello, buscó el final de la hegemonía imperante, casi dictatorial, minimizando la violencia y reponiendo las ideas de justicia, igualdad y participación ciudadana en una comunidad que carecía de los medios necesarios para garantizar la convivencia en la polis. La meta era alcanzar un equilibrio en las relaciones sociales, así como reconducir a los atenienses hacia la unidad y la concordia, devolviendo a todos los ciudadanos sin excepción su sentido de pertenencia a la polis. A ello contribuyó su idea de eunomía, que constituye una parte importante de su teoría política y que ofrece una perspectiva innovadora en cuestiones de gobierno. Su planteamiento exigía al político conocer las aspiraciones de los ciudadanos, pero también el orden inmanente que se produce en la naturaleza (physis) tal como la concebían los primeros filósofos durante ese mismo tiempo. La naturaleza se rige por las leyes de la necesidad, lo que explica que las normas sean estables y su cumplimiento inexorable. En cambio, la vida humana se rige por las normas de la libertad. Estas pueden cambiar pese a tener un fondo de estabilidad, porque la aceptación social de las nuevas leyes no puede ser impuesta, sino que debe ser fruto de la integración y el desarrollo de la comunidad política.

Solón supo que debía sopesar con la máxima atención sus reformas, asegurándose que no beneficiaran o perjudicaran de forma injustificada a ninguna de las clases enfrentadas a las que pretendía armonizar en un proyecto político y social compartido. Y, para no generar movimientos en su contra, expuso sus ideas dentro de un marco intelectual y cultural con el que los atenienses pudieran identificarse o, cuanto menos, no despertar la animadversión de la clase dominante. 
Las alternativas políticas fundamentales para Solón no se restringían a la tensión social entre las formas políticas como la monarquía, la oligarquía y la democracia, sino entre soberbia y honestidad, orgullo y modestia, arrogancia y humildad, justicia y fuerza, así como a la ausencia de leyes y el establecimiento de unas leyes correctas. Era preciso que los gobernantes actuaran de forma justa y correcta. Solón estimó que un medio esencial para conseguirlo era la protección de la condición libre del hombre con unas leyes escritas basadas en la justicia, que fueran capaces de hacer discurrir a la política por unos cauces que preservaran y garantizaran la realización social del orden justo y legal dentro de la comunidad. Así, consiguió una mezcla equilibrada entre análisis, teoría y acción políticas en un proceso ordenado e interconectado temporalmente.

La idea que Solón transmitió fue que la disnomía acarrea siempre una serie larga de males a las personas, a las instituciones y a las comunidades. En cambio, la eunomía representa el régimen político correcto, ordenado y justo, cuyas instituciones son adecuadas, tanto para permitir la participación política de los ciudadanos como para garantizar su libertad de actuación. De este modo, desde la segunda se evitarían los males sociales que Solón denunciaba en su consideración de la polis. Por consiguiente, se podría deducir que el buen orden se caracteriza por el respeto mutuo de los miembros de las clases sociales, por la limitación del desmedido afán por maximizar las ganancias y el beneficio, por el seguimiento exacto de las leyes y por establecer una armonía permanente entre los ciudadanos.

Los versos también denotan su firme convicción de haber logrado satisfacer los requerimientos señalados en la consecución de una sociedad más coordinada y armónica. Se trata de una lírica que remite con asiduidad a la justicia $\left(d_{i k e}\right)^{50}$, alegando lo que es apropiado a cada clase. La primacía de la justicia señala lo que es conveniente y esto lo consideró Solón en sus reformas. Según su propio convencimiento, unificando el uso de la fuerza coactiva del poder político, controlada por los mandatos y las exigencias de la justicia y, al mismo tiempo, estableciendo un sistema jurídico que sirviera para ordenar la convivencia entre todos los grupos sociales del Ática ${ }^{51}$. Si contemplamos con más detalle lo que corresponde al pueblo, comprendemos que sus logros más importantes fueron: la libertad individual y la participación activa en el devenir social y político de la comunidad, el poder formar parte de los tribunales de apelación, tener garantizado un mínimo vital suficiente y, en cierta manera, no estar subordinado

\footnotetext{
${ }^{50}$ SOLÓN, fragmentos 1. 29-32 y 43-65.

${ }^{51}$ Solón, fragmento 16.
} 
a los caprichos de la aristocracia, toda vez que la justicia la ejercían los órganos de gobierno de la polis basándose en las leyes ${ }^{52}$.

La teoría política de Solón implicaba la observancia de un cierto comportamiento moral como garantía del orden jurídico-estatal. Por consiguiente, consideró necesaria la toma de medidas concretas para prevenir cualquier planteamiento inmoral. Su cumplimiento se propició no solamente a través de las advertencias éticas dirigidas a los ciudadanos, sino aprovechando los efectos secundarios de las mismas reformas que, en cierto modo, beneficiaron la promoción de la moral ciudadana. En el orden social proyectado por Solón, ciertas conductas injustas no podían dejarse sin castigo y pasaron a ser perseguidas por vía judicial. Así sucedió con la esclavitud y la explotación rigurosa de deudores, que se consideraron un mal social y político. Para evitar que el ser humano fuera tratado de forma injusta y abusiva, se pusieron los medios para lograr una cierta felicidad y tranquilidad mediante la estabilidad social y el respeto a la libertad personal de cada ciudadano. Esta felicidad consistía en llevar una vida familiar sosegada, en el cultivo de las amistades, en el disfrute de una cierta prosperidad $\mathrm{y}$ en la seguridad de poder satisfacer en todo momento las necesidades naturales y primarias, lo que permitió el regreso de no pocos atenienses deportados y hasta vendidos que, según Solón, "de haber rodado por tantos sitios, ya no hablaban el dialecto ático" 53 .

Solón se ganó la fama de hombre de Estado porque persiguió el interés común de todos los miembros de la polis de una manera racional, estableciendo pautas de comportamiento, instituciones adecuadas y unas leyes que eran convenientes para el pueblo, aunque este no viera cumplidas en ellas todas sus expectativas. Dichas leyes, grabadas en estelas rotatorias de madera, se colocaron en un lugar muy visible y frecuentado por los atenienses. Se dispuso que estas fueran interpretadas conforme a las exigencias del texto legal y las circunstancias que concurriesen en cada caso, es decir, se estableció la jurisprudencia como forma de resolver los conflictos. La validez de tal legislación abarcaría cien años. La polis, con sus instituciones y los mismos ciudadanos, sería la que velaría y garantizaría su cumplimiento ${ }^{54}$.

${ }^{52}$ LEwIS, Solon the Thinker, pp. 62-68.

${ }^{53}$ SOLÓN, fragmento 24. 10-11.

${ }^{54}$ Aristóteles, Constitución de los atenienses 7. 1-2; Plutarco, Vidas Paralelas. Solón 25, 92. Pero a la primera oportunidad los atenienses se olvidaron de todo lo que habían conseguido y prefirieron entregar la responsabilidad de gobierno a un tirano como Pisístrato. El hecho muestra que Solón falló como pedagogo de la política y sus reformas no calaron de forma tan profunda en el pueblo. 
En el establecimiento del nuevo orden político y jurídico partió de la hipótesis de que la aptitud para desempeñar cargos políticos viene condicionada por ciertas capacidades intelectuales y, también, por la independencia económica. Debido a las nuevas exigencias en cuanto a las tácticas militares, así como a la crisis económica, el viejo sistema de la aristocracia se mostraba obsoleto. Por el contrario, el sistema timocrático podía satisfacer las nuevas necesidades de la comunidad política que estaba naciendo, pero con algunos rasgos democráticos que permitían cierta participación en las decisiones políticas a los ciudadanos que habían quedado al margen de la sociedad en el viejo régimen aristocrático. Con estos cambios Solón pretendió que todos los ciudadanos se sintieran integrados, responsables y comprometidos con el desarrollo político de su comunidad.

A pesar de este esfuerzo reformador en todos los sentidos, el arconte no consiguió terminar con las disputas sociales, lo cual demuestra la dificultad que existe siempre para resolver la división entre los ciudadanos, que genera inestabilidad social y una permanente agitación política. El orden político ideado por Solón para estructurar la vida de Atenas fue lógicamente criticado por las diferentes facciones, en el sentido que ninguna de ella veía satisfechas todas sus expectativas, aunque sí algunas relevantes. Con posterioridad a Solón, la vida política de Atenas se alejó de forma clara de las reformas y de las exigencias morales impuestas por él, en la misma medida en que se agudizaron los males, las situaciones de crisis y los continuos enfrentamientos sociales. La estabilidad social de Atenas y su conversión en una institución política perdurable no llegó hasta el siglo quinto, gracias a las reformas llevadas a cabo por Clístenes ( $c a$. 570-507 a. e. c), una vez más con la oposición de la aristocracia.

Solón, después de terminar su mandato y sus reformas, realizó un viaje por Egipto y Chipre. Cuando regresó a Atenas, Pisístrato se había convertido en el portavoz de una masa popular muy numerosa y pobre que vivía en las regiones montañosas de Ática. Este líder político preparaba clandestinamente una revolución social para establecer un régimen tiránico apoyado en sus muchos partidarios. Solón recelaba de las intenciones de Pisístrato y trató de impedir sin éxito su toma del poder ${ }^{55}$, si bien el primero no llegó a sufrir ningún castigo. Parece que incluso el tirano solicitó su consejo y colaboración ${ }^{56}$. Aproximadamente dos años después de la llegada al poder de Pisístrato, Solón murió, al parecer, durante un nuevo viaje a Chipre hacia el año 560.

${ }^{55}$ Como dice Solón en el fragmento 24. 20-23, los pueblos tienden a la tiranía, a ser sometidos a un poder sin límite y en el que confían ciegamente.

${ }^{56}$ Aristóteles, Constitución de los atenienses, 14. 2-3; Plutarco, Vidas Paralelas. Solón 29, 94-95, 30-31, 96, según este último testimonio parece que Solón aceptó la oferta, pero es dudo- 


\section{REFLEXIONES FINALES}

Solón fue nombrado arconte para rescatar a Atenas de una situación muy crítica. Muchos ciudadanos libres se habían convertido en esclavos porque no podían pagar sus préstamos. La producción agrícola, base de la economía y el desarrollo del Ática, era muy escasa y las tierras estaban agotadas. El régimen político se había convertido en una oligarquía económica — con un acusado individualismo- que sometía por la fuerza a una mayoría de trabajadores que carecían de recursos y que se veían obligados a obedecer sus dictados. Los oligarcas actuaban exclusivamente buscando los intereses de su clase o de sus familias. Esta situación se iba generalizando en el Ática y amenazaba la perdurabilidad de la polis y su supervivencia. La desaparición de la monarquía como forma de Estado dejó un vacío que no rellenó otro régimen. La única solución era establecer una nueva forma de Estado y de gobierno en la que los ciudadanos participaran de forma más activa en las decisiones políticas y en el gobierno de la comunidad. Sin embargo, tal pretensión se frustraba una y otra vez porque la oligarquía económica dominante y dominadora amenazaba con acabar con estas expectativas, admitiendo el individualismo como principio normativo básico de la organización social.

El individualismo y la tiranía no cabían en la teoría política de Solón. Por esta razón, al afirmar que establecía leyes y realizaba reformas "ajustando a cada uno la recta justicia", Solón trataba de mostrar que tanto las leyes como las normas que ordenan el comportamiento social y la justicia obligan a todos por igual. $\mathrm{Su}$ pensamiento en este caso, como en otros muchos, se anticipó a la noción clásica de polis, que fue el gran legado de la teoría y la práctica política griega. La polis, para este autor, es anterior y más importante que el ciudadano. Los intereses del individuo, entendido como sujeto activo en la política, tienen que coincidir y estar siempre subordinados a los de su comunidad. Es este uno de los grandes aportes teóricos de Solón: admitir la existencia de un bien social independiente y superior al bien de los individuos, por el que hay que luchar preservándolo con las leyes más convenientes para la comunidad.

Esta actitud responde a una cuestión que tendrá gran importancia en todos los tiempos y es una constante en la historia de la teoría política: ¿por qué y en qué medida los intereses individuales han de estar sometidos a las decisiones

so que así fuera porque criticó a la persona y al régimen previniendo a los atenienses de sus consecuencias. De ser cierta la noticia habría que situar la colaboración de Solón en los primeros momentos, cuando el tirano aparentaba la suficiente benevolencia y racionalidad en la toma de medidas como para lograr su inicial aquiescencia. 
políticas de otras personas? La respuesta no la planteó Solón buscando una justificación en el origen noble del aspirante a gobernar. Es decir, no existía razón alguna para afirmar que un aristócrata por su nacimiento posee la capacidad para ejercer el gobierno de una comunidad. Ante la ausencia de ese criterio, que fue válido durante siglos, la justificación hay que buscarla en el plano de la legitimidad y de la legalidad unidas a la capacidad de las personas para desempeñar los cargos políticos. El planteamiento supone una revolución e introdujo una diferencia política, porque se cuestionó la competencia de un noble o de un gobernante para asumir las responsabilidades de un cargo, de un juez para dictar sentencias o para interpretar la ley. Esta nueva idea se basó en el procedimiento legal y en la consideración ética de la idoneidad de la persona para el desempeño del cargo y de la responsabilidad inherente al mismo.

Con este planteamiento, Solón se nos muestra como el primer pensador que trató de desarrollar una teoría política basada en unos principios éticos y jurídicos — legalidad y legitimidad - que sirvieran para mejorar la vida de los ciudadanos y conseguir el ideal de estabilidad y continuidad de los proyectos y de la comunidad política. Aun viviendo en un momento histórico y social delicado y difícil, trató de analizar la situación que quería mejorar. Descubrió sus fallos, los valoró y propuso soluciones, pasando del análisis de la experiencia social a la formulación de una teoría que debía servir de guía para proponer, instaurar y desarrollar medidas concretas que permitieran superar las dificultades y los problemas.

En poco tiempo, más o menos un año, que es lo que duraba el arcontado, consiguió reconducir la situación política y social de Atenas estableciendo la unidad, el compromiso y la concordia entre los ciudadanos. Devolvió a todos los atenienses, sin excepción, su sentido de pertenencia a la polis. Extendió la libertad social, eliminando las servidumbres y la posibilidad de ser reducido a la condición de esclavo por deudas. Pero, sobre todo, restituyó la libertad política reconociendo derechos, en su sentido más amplio, que evitaban la arbitrariedad de los magistrados y de los gobernantes en el desempeño de sus funciones.

La primera idea que nos revela Solón es que en Atenas se produjo, probablemente por su intervención, un equilibrio entre la iniciativa individual y el establecimiento de una comunidad política en la que todos los ciudadanos tenían la posibilidad de participar. Formar parte de esta comunidad exigía a los ciudadanos participar activamente en el gobierno y en la toma de decisiones políticas, de esta manera el ateniense formaba y se sentía parte inescindible de una realidad social y comunitaria que le superaba, que garantizaba su existencia y posibilitaba su desarrollo. Por eso, la polis era considerada la mejor forma de organización política. Esta idea de pertenencia fue esencial para conseguir restablecer el equilibrio social, la paz interna de la ciudad, sentar las bases del desarrollo económi- 
co y, sobre todo, alcanzar el reconocimiento de los derechos políticos y sociales de todos los ciudadanos, una idea que se fue consolidando gracias a las reformas legislativas que impulsó y llevó a cabo Solón ${ }^{57}$.

Como muestra con claridad Aristóteles, Solón fue un legislador singular e innovador. No deseó provocar un cambio político desde arriba hacia abajo, es decir, una imposición de sus ideas, principios y soluciones, sino que trabajó en aquello que podría realizar sin generar una revolución que provocara la inestabilidad política y social. Trató de persuadir a los atenienses de que fueran aceptando cambios paulatinos sin suscitar rechazo ni fomentar controversias sociales. Siempre que pudo, utilizó eufemismos para no encrespar el ánimo de los atenienses, por ejemplo, a los impuestos los denominó contribuciones. Mezcló de forma equilibrada en sus escritos, y posiblemente también en sus intervenciones públicas, lo dulce con lo amargo, la justicia con la fuerza, con el fin de alcanzar sus objetivos. Por ejemplo, cuando le preguntaron si él había hecho las mejores leyes que podía para los atenienses, respondió que eran las mejores que ellos podían recibir y aceptar. Si se hubiera excedido o hubiera pretendido llegar más lejos, quizás habría fracasado o provocado una revolución indeseada.

Solón introdujo otro elemento nuevo en la reflexión política: la racionalidad. Mediante análisis, diagnosticó que los males que aquejan a las ciudades y, por ende, a los ciudadanos, son muchos y se incrementan por la imprudencia de los hombres. Así, los errores de los hombres son los que provocan la ruina de la ciudad y no el castigo de los dioses. El hombre debe adquirir conciencia de su libertad para actuar, pero también de la responsabilidad inherente de sus acciones. La solución a estos problemas exigía que Solón en su obra realizara el tránsito desde la fatalidad teológica a la racionalidad política ${ }^{58}$. Su éxito es fruto del análisis certero de la situación, del uso de los medios que sirven para superar los problemas y de la aplicación del tratamiento adecuado a los problemas con los que se enfrentaba y tenía que resolver.

El reto que el mismo Solón se impuso a sí mismo fue muy importante. Partiendo de que es ineludible que exista una organización política adecuada a las exigencias del ser humano como es la polis, afirmó como requisito imprescindible para la realización completa de la humanidad la capacidad del hombre para vivir y convivir con otros en un espacio común y propio, a través de la construcción de un

${ }^{57}$ Werner JAEGER, Paideia. Los ideales de la cultura griega, FCE, México, 1974, pp. 137-139.

${ }^{58}$ Solón, fragmento 1. 63-66; LEWIS, Solon the Thinker, pp. 89-90. 
proyecto social y político que a todos conviniera y beneficiara ${ }^{59}$. Buscó cuál podía ser la mejor polis, la comunidad política más adaptada al modo de ser del hombre, siguiendo un proceso que, como se ha dicho, va del análisis a la formulación de una teoría política, para concluir en unas actuaciones institucionales que concretaran los cambios realizados para así darles estabilidad y perdurabilidad.

No cabe duda de que Solón fue un político con extraordinaria capacidad para el análisis de la realidad, para buscar soluciones y gobernar. Supo gestionar los asuntos públicos y comunicar sus proyectos a los ciudadanos para comprometerlos en ellos. No rehusó enfrentarse a los problemas acuciantes y desarrolló un liderazgo reconocido por los atenienses.

Este poeta, estadista, legislador y sabio ha trascendido la línea de su tiempo histórico y su ejemplo vive todavía hoy en la memoria colectiva de los europeos, como modelo de lo que todo político y ser humano debe realizar cuando asume las responsabilidades de dirigir una comunidad, sirviéndola en todo y no sirviéndose de ella para su beneficio personal. La figura de Solón como pensador y legislador emerge por encima de sus poemas. Los clásicos griegos, los romanos, e incluso, por ejemplo, los padres fundadores de los Estados Unidos de América, lo consideraron como un gran pensador ${ }^{60}$. Platón (ca. 427-347 a. e. c.) lo entronizó entre los Siete Sabios de Grecia ${ }^{61}$; Aristóteles pensó que él era entre todos los legisladores el más competente, acertado y ocurrente ${ }^{62}$; Demóstenes (ca. 380-320 a. e. c.) lo utilizó como defensor de las ideas políticas genuinamente griegas contra todos sus oponentes ${ }^{63}$; Cicerón ( $c a \cdot 106-43$ a. e. c.) lo consideró como una fuente imprescindible para la formación del Derecho que regía en la República Romana ${ }^{64}$; Plutarco lo tuvo como un modelo e icono moral; James

${ }^{59}$ Cabría preguntarse si Aristóteles partió de esta tesis de Solón para formular su conocida afirmación de que el hombre es un animal político o social. Para una exposición detallada de esta tesis puede consultarse el artículo de Salvador Rus Rufino y Francisco Arenas Dolz, “¿Qué sentido se atribuyó al zoon politikon de Aristóteles? Los comentarios medievales y modernos a la Politica: Foro Interno, n. ${ }^{\circ} 13$ (2013), pp. 91-118.

${ }^{60}$ Heródoto lo presenta en su obra ante Creso como un sabio y prudente consejero, Heródoto I, 29-33 y I, 86.

${ }^{61}$ Platón, Timeo 21 b-c, Critias 113a y Protágoras 343 c. Bruno Snell, Leben und Meinungen der Sieben Weisen (1938), Heimeran, München, 1952.

${ }^{62}$ Aristóteles, Politica 1273b-1274a 1-22.

${ }^{63}$ Demóstenes, 19, 252 y $18,6$.

${ }^{64}$ Cicerón, Leyes 2, 28. 
Madison (1751-1836) lo admiró como un legislador inmortal y, finalmente, Woodrow Wilson (1856-1924) dijo que él había otorgado a Atenas una constitución estable, porque no estaba sometida a los cambios que dictan el parecer y el capricho de los políticos de turno, en suma, una constitución que podría considerarse modelo para todas las constituciones posteriores ${ }^{65}$.

${ }^{65}$ En la obra de John E. Rexine, Solon and his Political Theory. The Contemporary Significance of a Basic Contribution to Political Theory by One of the Seven Wise Men, William Friedrick Press, New York, 1958, trató de mostrar cómo las ideas de Solón habían sido recogidas por otros autores y por políticos en activo para conformar sus propuestas. 